\title{
Association of self-reported sedentary time with insulin resistance among Korean adults without diabetes mellitus: a cross- sectional study
}

Kyeong Seok Kim ${ }^{1+}$, Seong Jun Kim ${ }^{1+}$, Seonggwan Kim ${ }^{1}$, Dong-Woo Choi ${ }^{2,3}$, Yeong Jun Jü 2,3,5* (D) and Eun-Cheol Park ${ }^{3,4,6^{*}}$

\begin{abstract}
Background: A more sedentary lifestyle can result in insulin resistance. However, few research studies have assessed the association between insulin resistance and sedentary lifestyle in Asian populations. Therefore, this study aimed to investigate the association of sedentary time with insulin resistance. In addition, we also investigate the moderate effect of employment status, moderate-to-vigorous physical activity (MVPA), and body mass index (BMI) in this association.

Methods: Data from 2573 individuals who participated in the 2015 Korean National Health and Nutrition Examination Survey were analyzed. Sedentary time was measured using self-administered questionnaires, and IR data were estimated using the homeostasis model assessment-insulin resistance index (HOMA-IR). Adjusted odds ratio (OR) and 95\% confidence intervals (Cls) from a multivariable logistic regression model were generated for all participants. Subgroup analysis was only performed between sedentary time and HOMA-IR stratified by employment status, because moderate effects were not significant in the tests for interaction for MVPA and BMI. For all analyses, the individuals were categorized as having high or normal HOMA-IR values ( $>1.6$ and $\leq 1.6$, respectively).

Results: A HOMA-IR $>1.6$ was observed in $40.3 \%$ of the sedentary time Q1 (low) group ( $<5.0 \mathrm{~h} /$ day), $41.4 \%$ of the sedentary time Q2 (middle-low) group, $44.2 \%$ of the sedentary time Q3 (middle-high) group, and 48. $4 \%$ of the sedentary time Q4 (high) group ( $\geq 10.0 \mathrm{~h} /$ day). When the low level sedentary time group was used as the reference group, the high level sedentary time group was significantly associated with high IR value (HOMA-IR > 1.6) $(\mathrm{OR}=1.40,95 \% \mathrm{Cl}: 1.060-1.838)$. However, this association was not significant across the other sedentary time groups. Moreover, participants reporting a high sedentary time and were employed had 1.67 times the odds of having a high IR value (HOMA-IR > 1.6) compared to those who reported having a low sedentary time and were employed $(\mathrm{OR}=1.67,95 \% \mathrm{Cl}$ : 1.184-2.344). In the unemployed participants, sedentary time was not associated with IR.

Conclusions: High sedentary time ( $\geq 10.0 \mathrm{~h} /$ day) was associated with elevated HOMA-IR among Korean adults without diabetes mellitus. Furthermore, the association between high sedentary time and HOMA-IR values was more pronounced in the employed population.
\end{abstract}

Keywords: Insulin resistance, HOMA-IR, Sedentary time

\footnotetext{
* Correspondence: joomeon@gmail.com; ecpark@yuhs.ac

${ }^{\dagger}$ Kyeong Seok Kim and Seong Jun Kim contributed equally to this work.

2Department of Public Health, Graduate School, Yonsei University, Seoul,

Republic of Korea

${ }^{3}$ Institute of Health Services Research, Yonsei University College of Medicine,

50 Yonsei-ro, Seodaemun-gu, Seoul 03722, Republic of Korea

Full list of author information is available at the end of the article
}

(c) The Author(s). 2018 Open Access This article is distributed under the terms of the Creative Commons Attribution 4.0 International License (http://creativecommons.org/licenses/by/4.0/), which permits unrestricted use, distribution, and reproduction in any medium, provided you give appropriate credit to the original author(s) and the source, provide a link to the Creative Commons license, and indicate if changes were made. The Creative Commons Public Domain Dedication waiver (http://creativecommons.org/publicdomain/zero/1.0/) applies to the data made available in this article, unless otherwise stated. 


\section{Background}

Insulin resistance (IR) occurs when the body's response to insulin is lower than normal. The deterioration of insulin makes the cells unable to burn glucose effectively, which causes the body to over-produce insulin and contribute to the occurrence of various diseases [1, 2]. IR plays a key role in the development of type 2 diabetes and contributes to the pathophysiology of burdensome disease including obesity, metabolic syndrome, and cardiovascular disease. IR is commonly considered an important clinical and biochemical determinant and has been a subject of interest, as it has effects on various chronic disease such as diabetes, cardiovascular disease, hypertension, and metabolic syndrome [3]. For example, previous studies have reported that family history of type 2 diabetes mellitus (T2DM), non-alcoholic fatty liver disease, obesity, lack of exercise, high triglyceride levels, low levels of high-density lipoprotein, high-molecular weight (HMW)-adiponectin levels, hepatitis C, hemochromatosis, or hypercortisolism are associated risk factors [4-9]. Studies on insulin resistance have been reported in neuroscience and clinical research fields. Studies on insulin resistance reported that IR is associated with cognitive dysfunction such as cognitive decline and cognitive impairment [10].

Meanwhile, recent studies have focused on factors such as lack of exercise and a sedentary lifestyle in relation to insulin resistance [11]. Studies have reported that poor physical activity status is associated with insulin resistance, with attention being focused on sitting time which is directly related to physical activity status [12]. Recently, the need to investigate the relationship between sitting time and health status is increasing, and it is also necessary to establish a basis for this research. Sedentary time has a significant effect on health, and individuals who use more screen-based entertainment have a higher risk of clinically confirmed cardiovascular disease events [13]. Furthermore, a cohort study of people from Hawaii and California revealed that sedentary time was associated with cancer mortality [14]. A meta-analysis from 2015 revealed that sedentary time was associated with cardiovascular disease and all-cause mortality [15], and another meta-analysis from 2012 also demonstrated that sedentary time was associated with various diseases including type II diabetes [16].

In addition, few research have evaluated the association between sedentary time and IR in the Korean population, and most studies regarding sedentary lifestyle and diabetes during 2012-2015 only evaluated non-Asian populations $[17,18]$. To fill this research gap, there is a need to investigate studies on this topic in Asian population. Therefore, the purpose of this study was to investigate the association of sedentary time with insulin resistance.
Meanwhile, physical activity and BMI are well-known factors that are independently associated with insulin resistance [19-21]. In addition, as second longest working hours in OECD countries, high sedentary time are becoming a lot of controversy in Korea. Hence, we also investigate the moderate effect of employment status, moderate-to-vigorous physical activity (MVPA), and body mass index (BMI) in this association.

\section{Methods}

\section{Study population}

The present study evaluated data from the 2015 Korean National Health and Nutrition Examination Survey (KNHANES), which was performed by the Korean Center for Disease Control. A cross-sectional survey, it is a multistage, stratified area probability sample of civilian non-institutionalized Korean households by geographic area, age, and gender groups. This survey is composed of three parts-a health interview, health examination, and nutrition survey-all of which were performed by trained medical staff and dieticians. A total of 7380 individuals participated in the 2015 KNHANES. However, the present study excluded participants with diabetes (fasting blood glucose levels $>126 \mathrm{mg} / \mathrm{dL}$, or physician-diagnosed diabetes mellitus), in order to avoid confounding the IR-related analyses [22]. In addition, participants were excluded if they were missing data and if they were aged < 19 years. Any respondents who did not provide data on sedentary time, moderate-to-vigorous physical activity (MVPA), subjective health status, age, income, employment status, education, stress, smoking, drinking, marriage status, BMI, menopause, or who were aged $<19$ years were excluded from the study (see details in Fig. 1).

The KNHANES data are openly available at the KNHANES website: https://knhanes.cdc.go.kr/knhanes/ eng/index.do. Ethical approval for this study was granted by the institutional review board (IRB) of the KCDC Seoul, Korea (IRB \#: 2015-01-02-6C).

\section{Measures \\ HOMA-IR}

The dependent variable was defined as the homeostasis model assessment-insulin resistance index (HOMA-IR), which was calculated using the following formula:

$H O M A-I R=\frac{\text { fasting plasma glucose }(\mathrm{mg} / \mathrm{dL}) \times \text { fasting plasma insulin }(\mu \mathrm{IU} / \mathrm{mL})}{405}$

Data regarding fasting plasma glucose and insulin levels were obtained from the 2015 KNHANES health examination results. For the present study, individuals were categorized as having high or normal HOMA-IR values ( $>1.6$ vs. $\leq 1.6$, respectively) based on the Japanese Diabetes Society guidelines [23]. 


\section{KNHANES 2015}

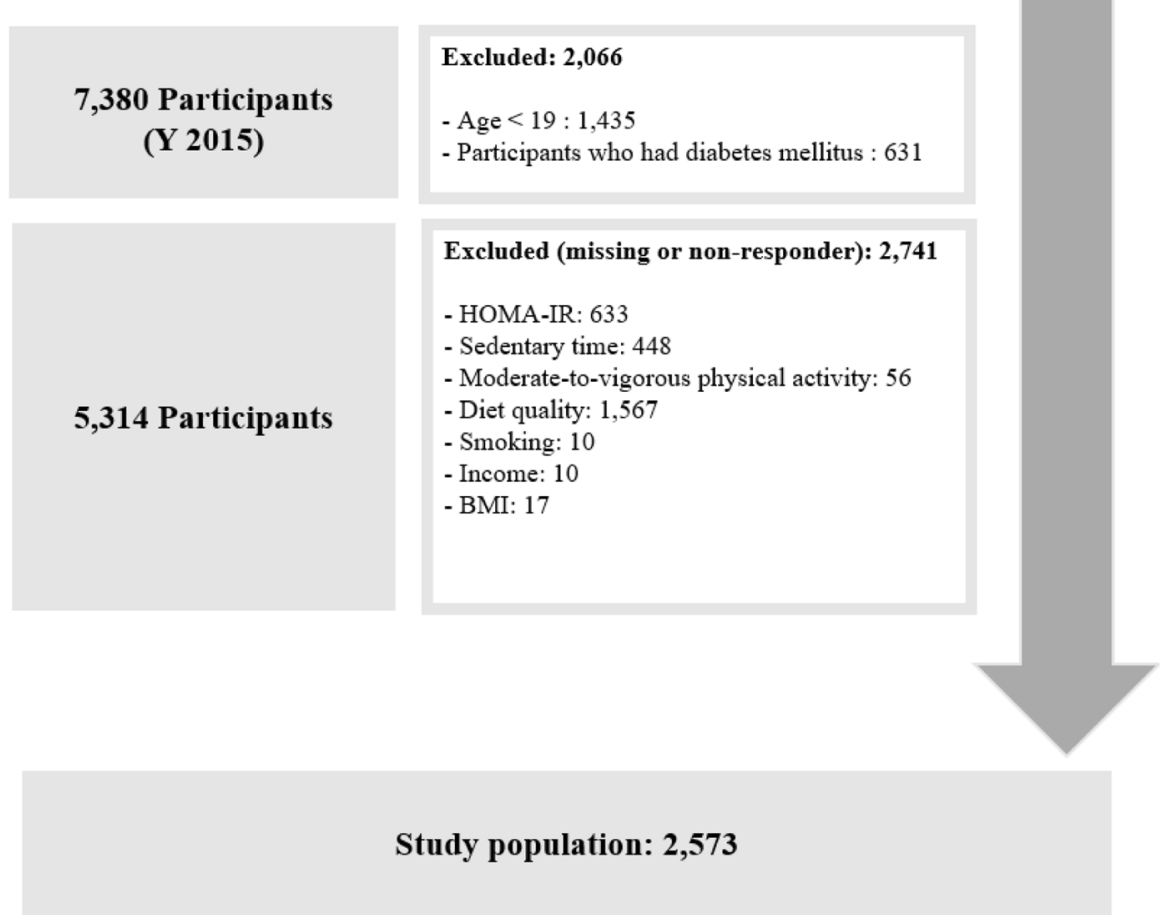

Fig. 1 Is the flow diagram of the study participants for present study

\section{Sedentary time}

The independent variable was defined as sedentary time. Sedentary time was estimated using the Global Physical Activity Questionnaire (GPAQ), and assessed via the following question: "How much time do you spend sitting or lying down during at work, at home, when travelling from place to place or when meeting friends, but excluding sleeping hours?". Responses were divided into 4 categories using quartiles, with the Q1 group having $<5 \mathrm{~h} /$ day, the Q2 group having 5-7.9 h/day, the Q3 group having 8-9.9 h/day, and the Q4 group having $\geq 10 \mathrm{~h} /$ day. The validity of the GPAQ tool for Koreans was 0.79 , which was reported to be sufficiently valid for the use of the tool [24].

\section{MVPA}

MVPA was measured using the GPAQ. GPAQ, developed by the World Health Organization (WHO), is a questionnaire measuring the amount of physical activity (occupation, mobility, leisure activity) and is a standardized questionnaire currently used in 50 countries. This questionnaire was developed and validated by the WHO to systematically monitor global physical activity levels as one of the main lifestyle disease risk factors. The validity of the GPAQ tool for Koreans was 0.64, which was reported to be sufficiently valid for the use of the tool
[24]. Regarding MVPA, responses were divided into 2 categories ("yes" or "no"), with the "yes" group consisting of individuals who exercise moderately more than 2 hours and 30 minutes per week or intensively more than 1 hour and 15 minutes per week. 1 minute of intensive physical activity was defined as equivalent to 2 minutes of moderate physical activity.

\section{Diet quality}

To assess the diet quality, the mean adequacy ratio (MAR) index was calculated using the nutrient adequacy ratio (NAR) index. The NAR was calculated for each of nine nutrients (protein, vitamin A, thiamine, riboflavin, niacin, $\mathrm{Ca}, \mathrm{P}, \mathrm{Fe}$, and vitamin $\mathrm{C}$ ), whose recommended intake was set according to the dietary reference intakes for Koreans [25], using the following formula:

\section{$\mathbf{N A R}=$ Participant ${ }^{\prime}$ s daily intake of a nutrient /recommended nutrition intake}

$\mathbf{M A R}=\Sigma \mathrm{NAR} /$ number of nutrients.

NARs were truncated at 1 if the value was over 1 . The MAR provides an index of the overall diet quality. A high MAR implies a high-quality diet [26]. 


\section{Covariates}

The analyses were adjusted for covariates that might be associated with HOMA-IR. These covariates were defined as age (19-29 years, 30-49 years, 50-69 years, and $\geq 70$ years), sex, body mass index (BMI; underweight: $<18.5 \mathrm{~kg} / \mathrm{m}^{2}$, normal: $18.5-24.9 \mathrm{~kg} / \mathrm{m}^{2}$, and obese: $\geq 25.0$ $\mathrm{kg} / \mathrm{m}^{2}$ ), education level (elementary school or less, middle school, high school, and university or higher), income (monthly income quartiles), employment status (employed vs. unemployed or economically inactive), marital status (no vs. yes), subjective health status (good, normal, and bad) stress (no vs. yes), smoking status (current smoker, previous smoker, and never smoker), alcohol consumption (not in the last year, $<4$ times per month, 2-3 time per week, and 4 times per week), and MVPA (no vs. yes).

\section{Statistical analysis}

We first examined the distribution of each categorical variable. The chi-square test was used to calculate the distribution of each categorical variable and to confirm significant differences between groups. In addition, to produce an unbiased national estimate, a sample weight was assigned for the participating individuals to represent the Korean population. The sampling weight was calculated by accounting for the complex survey design, survey nonresponse, and post-stratification. Next, to investigate the association of sedentary time with insulin resistance, multivariable logistic regression analysis was used. In multivariable logistic regression, confounding variables such as age, sex, income, education level, employment status, marriage status, perceive health status, stress, smoking, alcohol intake, BMI, MVPA, and diet quality were controlled. To consider the considerable effect of employment status, MVPA, and BMI on sedentary behavior which has been reported in previous literature [27], we also examined whether employment status, MVPA, and BMI modified the association between sedentary time and the insulin resistance by introducing an interaction terms in the models. Then, subgroup analysis was only performed between sedentary time and HOMA-IR stratified by employment status, because moderate effects were not significant in the tests for interaction for MVPA and BMI variables.

All statistical analyses were performed using SAS software (version 9.4; SAS Institute, Cary, NC, USA), and differences with a $p$-value $<0.05$ were considered statistically significant.

\section{Results}

\section{Characteristics of the participants}

In our study, 2573 participants were included to access the association between sedentary time and HOMA-IR. Table 1 shows the characteristics of the study population.
Among the study population, $19.9 \%(n=511)$ were in the sedentary time Q1 (low) group ( $<5.0 \mathrm{~h} /$ day), 38.7\% ( $n=$ 997) were in the sedentary time Q2 (middle-low) group (5.0-7.9 h/day), $22.4 \%(n=577)$ were in the sedentary time Q3 (middle-high) group (8.0-9.9 h/day), and 19.0\% ( $n=$ 488 ) were in the sedentary time Q4 (high) group $(\geq 10.0 \mathrm{~h} /$ day). High IR values (HOMA-IR > 1.6) were observed for $40.3 \%(n=206)$ of the sedentary time Q1 (low) group, $41.4 \%(n=413)$ of the sedentary time Q2 (middle-low) group, $44.2 \%(n=255)$ of the sedentary time Q3 (middle-high) group, and $48.4 \%(n=236)$ of the sedentary time Q4 (high) group.

\section{Multivariable logistic regression results of association between ST and HOMA-IR}

Table 2 show the results of the multivariable logistic regression analysis for the association between sedentary time and HOMA-IR. High level of sedentary time $(\geq 10$ $\mathrm{h}$ /day) was significantly associated with high IR value (HOMA-IR > 1.6) (OR = 1.40, 95\% CI: 1.060-1.838).

\section{Sub-group analysis results by employment status}

The subgroup analysis results are shown in Table 3. Subgroup analysis was only performed between sedentary time and HOMA-IR stratified by employment status, because moderate effects were not significant in the tests for interaction for MVPA and BMI variables (MVPA: $p$ for interaction, $p=0.2679$; BMI: $p$ for interaction, $p=$ $0.2003)$. Subgroup analysis showed significant differences in employment status ( $p$ for interaction: $p=0.0217$ ). Participants reporting high sedentary time and were employed had 1.67 times the odds of having a high IR value (HOMA-IR > 1.6) compared to those who reported having a low sedentary time and were employed (OR = 1.67, 95\% CI: 1.184-2.344). In the unemployed participants, sedentary time was not associated with IR.

\section{Discussion}

Although there are many studies that showed that high sedentary time was negatively associated with health outcomes, little research has been conducted on this in Korea. Therefore, there is a growing interest in researching sedentary time. Thus, we investigate the association of sedentary time with IR in Korean adults without diabetes mellitus. In addition, we also investigate the moderate effect of employment status, MVPA, and BMI in this association. Given that these issues remain a concern, it is necessary to design effective strategies to prevent and manage reduced insulin resistance and its negative health outcomes.

Through multivariable analysis, our findings revealed that sedentary time was associated with IR among an adult population without diabetes mellitus. This was consistent with previous studies. Cross-sectional analysis 
Table 1 General characteristics of study population

\begin{tabular}{|c|c|c|c|c|c|c|c|}
\hline \multirow[t]{3}{*}{ Variables } & \multicolumn{2}{|l|}{ Total } & \multicolumn{4}{|c|}{ HOMA-IR > 1.6} & \multirow[t]{3}{*}{$P$ Value } \\
\hline & \multirow[b]{2}{*}{$\mathrm{N}$} & \multirow[b]{2}{*}{$\%$} & \multicolumn{2}{|l|}{$\overline{\mathrm{YES}}$} & \multicolumn{2}{|l|}{$\mathrm{NO}$} & \\
\hline & & & $\mathrm{N}$ & $\%$ & $\mathrm{~N}$ & $\%$ & \\
\hline Sedentary time (hours per day) & & & & & & & 0.0360 \\
\hline Q1 $(<5)$ & 511 & 19.9 & 206 & 40.3 & 305 & 59.7 & \\
\hline Q2 (5 7.9) & 997 & 38.7 & 413 & 41.4 & 584 & 58.6 & \\
\hline Q3 (8 9.9) & 577 & 22.4 & 255 & 44.2 & 322 & 55.8 & \\
\hline Q4 ( $\geq 10)$ & 488 & 19.0 & 236 & 48.4 & 252 & 51.6 & \\
\hline Age & & & & & & & 0.0010 \\
\hline $19 \sim 29$ & 488 & 19.0 & 225 & 46.1 & 263 & 53.9 & \\
\hline $30 \sim 39$ & 508 & 19.7 & 203 & 40.0 & 305 & 60.0 & \\
\hline $40 \sim 49$ & 623 & 24.2 & 243 & 39.0 & 380 & 61.0 & \\
\hline $50 \sim 59$ & 679 & 26.4 & 294 & 43.3 & 385 & 56.7 & \\
\hline$\geq 60$ & 275 & 10.7 & 145 & 52.7 & 130 & 47.3 & \\
\hline Sex & & & & & & & 0.0001 \\
\hline Male & 1006 & 39.1 & 481 & 47.8 & 525 & 52.2 & \\
\hline Female & 1567 & 60.9 & 629 & 40.1 & 938 & 59.9 & \\
\hline Income & & & & & & & 0.1138 \\
\hline Low & 566 & 22.0 & 261 & 46.1 & 305 & 53.9 & \\
\hline Middle low & 648 & 25.2 & 276 & 42.6 & 372 & 57.4 & \\
\hline Middle high & 684 & 26.6 & 305 & 44.6 & 379 & 55.4 & \\
\hline High & 675 & 26.2 & 268 & 39.7 & 407 & 60.3 & \\
\hline Education level & & & & & & & 0.0073 \\
\hline Elementary school or less & 212 & 8.2 & 112 & 52.8 & 100 & 47.2 & \\
\hline Middle school & 226 & 8.8 & 89 & 39.4 & 137 & 60.6 & \\
\hline High school & 1023 & 39.8 & 453 & 44.3 & 570 & 55.7 & \\
\hline University or more & 1112 & 43.2 & 456 & 41.0 & 656 & 59.0 & \\
\hline Employment status & & & & & & & $<.0001$ \\
\hline Employed & 1748 & 67.9 & 748 & 42.8 & 1000 & 57.2 & \\
\hline Unemployed or economically inactive & 825 & 32.1 & 362 & 43.9 & 463 & 56.1 & \\
\hline Marriage status & & & & & & & 0.2802 \\
\hline Unmarried & 597 & 23.2 & 269 & 45.1 & 328 & 54.9 & \\
\hline Married & 1976 & 76.8 & 841 & 42.6 & 1135 & 57.4 & \\
\hline Perceive health status & & & & & & & 0.0006 \\
\hline Healthy & 873 & 33.9 & 332 & 38.0 & 541 & 62.0 & \\
\hline Normal & 1322 & 51.4 & 597 & 45.2 & 725 & 54.8 & \\
\hline Unhealthy & 378 & 14.7 & 181 & 47.9 & 197 & 52.1 & \\
\hline Stress & & & & & & & 0.0060 \\
\hline No & 1807 & 70.2 & 748 & 41.4 & 1059 & 58.6 & \\
\hline Yes & 766 & 29.8 & 362 & 47.3 & 404 & 52.7 & \\
\hline Smoking & & & & & & & 0.0017 \\
\hline None smoker & 1660 & 64.5 & 675 & 40.7 & 985 & 59.3 & \\
\hline Previous smoker & 471 & 18.3 & 232 & 49.3 & 239 & 50.7 & \\
\hline Current smoker & 442 & 17.2 & 203 & 45.9 & 239 & 54.1 & \\
\hline
\end{tabular}


Table 1 General characteristics of study population (Continued)

\begin{tabular}{|c|c|c|c|c|c|c|c|}
\hline \multirow[t]{3}{*}{ Variables } & \multicolumn{2}{|l|}{ Total } & \multicolumn{4}{|c|}{ HOMA-IR > 1.6} & \multirow[t]{3}{*}{$P$ Value } \\
\hline & \multirow[b]{2}{*}{$\mathrm{N}$} & \multirow[b]{2}{*}{$\%$} & \multicolumn{2}{|l|}{ YES } & \multicolumn{2}{|l|}{ NO } & \\
\hline & & & $\mathrm{N}$ & $\%$ & $\mathrm{~N}$ & $\%$ & \\
\hline \multicolumn{7}{|l|}{ Alcohol intake } & \multirow[t]{5}{*}{0.7786} \\
\hline No & 539 & 20.9 & 243 & 45.1 & 296 & 54.9 & \\
\hline$<4$ times a month & 1545 & 60.1 & 657 & 42.5 & 888 & 57.5 & \\
\hline 2 3 times a week & 374 & 14.5 & 160 & 42.8 & 214 & 57.2 & \\
\hline$\geq 4$ times a week & 115 & 4.5 & 50 & 43.5 & 65 & 56.5 & \\
\hline \multicolumn{7}{|l|}{ BMI } & \multirow[t]{4}{*}{$<.0001$} \\
\hline Underweight $(\mathrm{BMI}<18.5)$ & 114 & 4.4 & 12 & 10.5 & 102 & 89.5 & \\
\hline Normal $(18.5 \leq \mathrm{BMI}<25)$ & 1666 & 64.8 & 533 & 32.0 & 1133 & 68.0 & \\
\hline Obesity ( 25 < BMI) & 793 & 30.8 & 565 & 71.3 & 228 & 28.7 & \\
\hline \multicolumn{7}{|l|}{ Moderate-to-vigorous physical activity } & \multirow[t]{3}{*}{0.1828} \\
\hline No & 1213 & 47.1 & 540 & 44.5 & 673 & 55.5 & \\
\hline Yes & 1360 & 52.9 & 570 & 41.9 & 790 & 58.1 & \\
\hline Diet quality (Mean \pm S.D) & \multicolumn{2}{|c|}{$0.83 \pm 0.16$} & \multicolumn{2}{|c|}{$0.83 \pm 0.16$} & \multicolumn{2}{|c|}{$0.83 \pm 0.16$} & 0.8722 \\
\hline Total & 2573 & 100.0 & 1110 & 43.1 & 1463 & 56.9 & \\
\hline
\end{tabular}

with 4757 adults in the United States of America reported that higher amounts of sedentary time was associated with higher HOMA-IR [28]. Another study that included 2027 young adult participants (aged 38-50 years) also confirmed that having higher amounts of sedentary time was cross-sectionally associated with higher HOMA-IR [29]. However, other studies reported that having higher amounts of sedentary time was not cross-sectionally associated with HOMA-IR or fasting insulin [30,31]. The differences in results might be explained by the differences between objectively measured time and small sample sizes.

Regarding subgroup analysis, it was only performed between sedentary time and HOMA-IR stratified by employment status, because moderate effects were not significant in the tests for interaction for MVPA and BMI variables. As the interaction tests proved to be statistically significant, we confirmed that the association

Table 2 Multivariable logistic regression analysis of the association between sedentary time and HOMA-IR

\begin{tabular}{lllll}
\hline Variables & HOMA-IR $>1.6$ & & \\
\cline { 2 - 4 } & Adjusted-OR & & \\
\hline & Sedentary time (hours per day) & & & \\
Q1 $(<5)$ & 1.00 & & & \\
Q2 (5 7.9) & 1.09 & 0.862 & - & 1.365 \\
Q3 (8 9.9) & 1.20 & 0.900 & - & 1.606 \\
Q4 ( $\geq 10)$ & 1.40 & 1.060 & - & 1.838
\end{tabular}

Notes: ${ }^{a}$ Adjusted odds ratios (OR) were calculated using logistic regression analysis and adjusted for age, sex, income, education level, employment status, marriage status, perceive health status, stress, smoking, alcohol intake, $\mathrm{BMI}$, moderate-to-vigorous physical activity, and diet quality between sedentary time with HOMA-IR values was more pronounced in the employed population. For most working adults, time spent sitting in the workplace is likely a greater contributor to overall sitting time [32]. In addition, studies reported that "work" was more sedentary and had less light-intensity activity than "non-work" $[33,34]$. Hence, the association between sedentary time and HOMA-IR in workers may be prominent due to prolonged sedentary time in work life. Therefore, there is a need to concentrate efforts to efficiently manage sedentary time, especially for workers. Recently, in an attempt to tackle the country's notoriously long work

Table 3 Subgroup analysis of the association between sedentary time and HOMA-IR by employment status

\begin{tabular}{|c|c|c|c|c|c|}
\hline \multirow[t]{2}{*}{ Variables } & & \multicolumn{4}{|l|}{ HOMA-IR > 1.6} \\
\hline & & \multirow[t]{2}{*}{ Adjusted-OR ${ }^{a}$} & \multicolumn{2}{|c|}{$95 \% \mathrm{Cl}$} & \\
\hline Employment status & Sedentary time & & & & \\
\hline \multirow[t]{4}{*}{ Employed } & Q1 (< 5) & 1.00 & & & \\
\hline & Q2 (5 7.9) & 1.22 & 0.928 & - & 1.597 \\
\hline & Q3 (8 9.9) & 1.24 & 0.872 & - & 1.769 \\
\hline & Q4 ( $\geq 10)$ & 1.67 & 1.184 & - & 2.344 \\
\hline \multirow{5}{*}{$\begin{array}{l}\text { Unemployed or } \\
\text { economically } \\
\text { inactive }\end{array}$} & Sedentary time & & & & \\
\hline & Q1 (< 5) & 1.00 & & & \\
\hline & Q2 (5 7.9) & 0.85 & 0.530 & - & 1.353 \\
\hline & Q3 (8 9.9) & 1.11 & 0.658 & - & 1.864 \\
\hline & Q4 ( $\geq 10)$ & 0.87 & 0.511 & - & 1.491 \\
\hline
\end{tabular}

Notes: a Adjusted odds ratios (OR) were calculated using logistic regression analysis and adjusted for age, sex, income, education level, marriage status, perceive health status, stress, smoking, alcohol intake, BMI, moderate-to-vigorous physical activity, and diet quality 
hours, South Korea officially dropped its maximum work week to $52 \mathrm{~h}$ in July 2018 in an effort to improve the quality of life among its citizens. As following strategies, approaches to effectively manage workers' own sedentary time during working hours should also be considered. Strategies should be supported to manage the sedentary time efficiently, such as providing support for the conditions for the physical activity of the workers in the workplace. Based on the lessons learned from many prior programs that aimed at efficient sedentary time management at the workplace, policy makers should consider efficient strategies to manage the sedentary time in the workplace [35].

The present study has several limitations that warrant consideration. First, individuals with diabetes were excluded because the vast majority of these patients receive diabetes treatments that can alter insulin sensitivity and HOMA-IR values. Although this approach is useful for data cleaning, it precludes any analysis of the association between sedentary time and HOMA-IR values among patients with diabetes, and further studies are needed to evaluate this issue. Second, the present study was unable to identify a causal relationship between sedentary time and insulin resistance because the study design was cross sectional and information was obtained via self-reported. Thus, prospective cohort studies or prospective clinical research studies are needed to examine the causal relationships between sedentary time, employment status, and HOMA-IR values. Third, it is possible that IR can change over time, even in cases with controlled sedentary time. For example, a previous study [36] revealed that interrupting sedentary time with short walks was associated with lower postprandial glucose and insulin levels among overweight/obese adults. Fourth, we could not measure mobility impairment that have been associated with sedentary time, due to limitations of data. This probably unreported population characteristic could have influenced the association between sedentary time and insulin resistance.

\section{Conclusion}

In conclusion, this study revealed that only high sedentary time $(\geq 10.0 \mathrm{~h} /$ day $)$ was associated with HOMA-IR among adults Korean without diabetes mellitus. However, this association was not significant across the other sedentary time groups. Furthermore, the association of high sedentary time ( $\geq 10.0 \mathrm{~h} /$ day) with HOMA-IR values was more pronounced in the employed population.

\section{Abbreviations}

BMI: Body Mass Index; GPAQ: Global Physical Activity Questionnaire; HOMAIR: Homeostasis Model Assessment-Insulin Resistance; IR: Insulin Resistance; MAR: Mean Adequacy Ratio; MVPA: Moderate-to-Vigorous Physical Activity; NAR: Nutrient Adequacy Ratio

\section{Acknowledgements}

None

Funding

None

Availability of data and materials

The KNHANES was openly available in (https://knhanes.cdc.go.kr/knhanes/ main.do) by submitting written oath and data utilization plan.

\section{Author's contributions}

KSK, SJK, and SKK participated in designing of the study and interpretation of data, and writing the initial manuscript SJK, and DWC participated in analyzing the data and reviewing the manuscript. YJJ oversaw the overall work process. YJJ and ECP is the guarantor of this work and takes responsibility for the integrity of the data and the accuracy of the data analysis and overall direction of the study. In addition, YJJ, and ECP involved in revising it critically for important intellectual content. All authors read and approved the final manuscript, and agreed to be accountable for all aspects of the study.

\section{Ethical approval and consent to participate}

Ethical approval for this study was granted by the institutional review board (IRB) of the KCDC Seoul, Korea (IRB \#: 2015-01-02-6C). As the KNHANES 2015 database does not contain private information and is openly available to researchers in de-identified format, we did not have to address ethical concerns regarding informed consent.

\section{Consent for publication}

Not applicable.

\section{Competing interests}

The authors have no conflicts. All authors declare no support from any organization for the submitted work, no financial relationship with any organization.

\section{Publisher's Note}

Springer Nature remains neutral with regard to jurisdictional claims in published maps and institutional affiliations.

\section{Author details}

${ }^{1}$ Premedical Courses, College of Medicine, Yonsei University, Seoul, Republic of Korea. ${ }^{2}$ Department of Public Health, Graduate School, Yonsei University, Seoul, Republic of Korea. ${ }^{3}$ Institute of Health Services Research, Yonsei University College of Medicine, 50 Yonsei-ro, Seodaemun-gu, Seoul 03722, Republic of Korea. ${ }^{4}$ Department of Preventive Medicine, Yonsei University College of Medicine, Seoul, Republic of Korea. ${ }^{5}$ Present address: Department of Preventive Medicine and Public Health, Ajou University School of Medicine, Suwon, Republic of Korea. ${ }^{6}$ Department of Preventive Medicine \& Institute of Health Services Research, Yonsei University College of Medicine, 50 Yonsei-ro, Seodaemun-gu, Seoul 120-752, Korea.

Received: 2 November 2017 Accepted: 20 November 2018 Published online: 04 December 2018

References

1. Lebovitz H. Insulin resistance: definition and consequences. Exp Clin Endocrinol Diabetes. 2001;109(Suppl 2):S135-48.

2. Chiu HK, Tsai EC, Juneja R, Stoever J, Brooks-Worrell B, Goel A, Palmer JP. Equivalent insulin resistance in latent autoimmune diabetes in adults (LADA) and type 2 diabetic patients. Diabetes Res Clin Pract. 2007;77(2):237-44.

3. Singh B, Saxena A. Surrogate markers of insulin resistance: a review. World J Diabetes. 2010;1(2):36.

4. Almeda-Valdes P, Cuevas-Ramos D, Mehta R, Gomez-Perez FJ, Cruz-Bautista I, Arellano-Campos O, Navarrete-Lopez M, Aguilar-Salinas CA. Total and high molecular weight adiponectin have similar utility for the identification of insulin resistance. Cardiovasc Diabetol. 2010;9(1):26.

5. Anderwald C, Anderwald-Stadler M, Promintzer M, Prager G, Mandl M, Nowotny P, Bischof MG, Wolzt M, Ludvik B, Kästenbauer T. The clamp-like index: a novel and highly sensitive insulin sensitivity index to calculate hyperinsulinemic clamp glucose infusion rates from oral glucose tolerance tests in nondiabetic subjects. Diabetes Care. 2007;30(9):2374-80. 
6. Kahn SE, Hull RL, Utzschneider KM. Mechanisms linking obesity to insulin resistance and type 2 diabetes. Nature. 2006;444(7121):840.

7. Grundy SM, Brewer HB, Cleeman JI, Smith SC, Lenfant C. Definition of metabolic syndrome: report of the National Heart, Lung, and Blood Institute/American Heart Association conference on scientific issues related to definition. Circulation. 2004;109(3):433-8.

8. Reaven GM, Chen Y-D, Jeppesen J, Maheux P, Krauss RM. Insulin resistance and hyperinsulinemia in individuals with small, dense low density lipoprotein particles. J. Clin. Invest. 1993;92(1):141-6.

9. Rao G. Insulin resistance syndrome. Am Fam Physician. 2001;63(6):1159-63 1165-1156.

10. Ma L, Wang J, Li Y. Insulin resistance and cognitive dysfunction. Clin Chim Acta. 2015;444:18-23.

11. Kolb H, S M. Environmental/lifestyle factors in the pathogenesis and prevention of type 2 diabetes. BMC Med. 2017;15(1):131.

12. Helmerhorst HJ, Wijndaele K, Brage S, Wareham NJ, Ekelund UJD. Objectively measured sedentary time may predict insulin resistance, independent of moderate and vigorous physical activity. Diabetes. 2009;58(8):1776-9.

13. Stamatakis E, Hamer M, Dunstan DW. Screen-based entertainment time, allcause mortality, and cardiovascular events: population-based study with ongoing mortality and hospital events follow-up. J Am Coll Cardiol. 2011; 57(3):292-9.

14. Kim Y, Wilkens LR, Park S-Y, Goodman MT, Monroe KR, Kolonel LN. Association between various sedentary behaviours and all-cause, cardiovascular disease and cancer mortality: the multiethnic cohort study. Int J Epidemiol. 2013;42(4): 1040-56.

15. Biswas A, Oh PI, Faulkner GE, Bajaj RR, Silver MA, Mitchell MS, Alter DA. Sedentary time and its association with risk for disease incidence, mortality, and hospitalization in adultsa systematic review and meta-analysissedentary time and disease incidence, mortality, and hospitalization. Ann Intern Med. 2015;162(2):123-32.

16. Wilmot EG, Edwardson CL, Achana FA, Davies MJ, Gorely T, Gray LJ, Khunti $K$, Yates T, Biddle SJ. Sedentary time in adults and the association with diabetes, cardiovascular disease and death: systematic review and metaanalysis. Diabetologia. 2012;55(11):2895-905.

17. Krishnan S, Rosenberg L, Palmer JR. Physical activity and television watching in relation to risk of type 2 diabetes: the black Women's health study. Am J Epidemiol. 2008;169(4):428-34.

18. Ford ES, Schulze MB, Kroeger J, Pischon T, Bergmann MM, Boeing $H$. Television watching and incident diabetes: findings from the European prospective investigation into Cancer and nutrition-Potsdam study. Journal of Diabetes. 2010;2(1):23-7.

19. Assah F, Brage S, Ekelund U, Wareham NJD. The association of intensity and overall level of physical activity energy expenditure with a marker of insulin resistance. Diabetologia. 2008;51(8):1399.

20. Risérus U, Ärnlov J, Berglund L. Long-term predictors of insulin resistance: role of lifestyle and metabolic factors in middle-aged men. Diabetes Care. 2007;30(11):2928-33.

21. Amati F, Dubé JJ, Coen PM, Stefanovic-Racic M, Toledo FG, Goodpaster BH. Physical inactivity and obesity underlie the insulin resistance of aging. Diabetes Care. 2009;32(8):1547-9.

22. American Diabetes Association. Standards of Med Care in Diabetes-2010. Diabetes Care. 2010;33(Suppl 1):S11-61.

23. Yamada C, Mitsuhashi T, Hiratsuka N, Inabe F, Araida N, Takahashi E. Optimal reference interval for homeostasis model assessment of insulin resistance in a Japanese population. Journal of diabetes investigation. 2011;2(5):373-6.

24. Jeon Y: Development of the Korean version of global physical activity questionnaire and assessment of reliability and validity. Academic research on task, Final Report, Korea Center for Disease Control and Prevention 2013. Center for Disease Control and Prevention 2013Center for Disease Control and Prevention 2013.

25. Ministry of Health and Welfare, The Korean Nutrition Society. Dietary reference intakes for Koreans 2015. Sejong; 2015. Available at [Korean language]: http://policy.nl.go.kr/cmmn/FileDown.do?atchFileld= 144045\&fileSn=23508. Accessed 25 Nov 2018.

26. Kant AK. Indexes of overall diet quality: a review. J Am Diet Assoc. 1996; 96(8):785-91.

27. O'donoghue G, Perchoux C, Mensah K, Lakerveld J, Van Der Ploeg H, Bernaards C, Chastin SF, Simon C, O'gorman D, Nazare J-A. A systematic review of correlates of sedentary behaviour in adults aged 18-65 years: a socio-ecological approach. BMC Public Health. 2016;16(1):163.
28. Healy GN, Matthews CE, Dunstan DW, Winkler EA, Owen N. Sedentary time and cardio-metabolic biomarkers in US adults: NHANES 2003-06. Eur Heart J. 2011;32(5):590-7.

29. Gibbs BB, Gabriel KP, Reis JP, Jakicic JM, Carnethon MR, Sternfeld BJDC. Cross-sectional and longitudinal associations between objectively measured sedentary time and metabolic disease: the coronary artery risk development in young adults (CARDIA) study. Diabetes Care. 2015;38(10):1835-43.

30. McGuire KA, Ross RJPO. Sedentary behavior is not associated with cardiometabolic risk in adults with abdominal obesity. PLoS One. 2011; 6(6):e20503.

31. Ekelund U, Brage S, Griffin SJ, Wareham NJ. Objectively measured moderate and vigourous intensity physical activitiy but not sedentary time predicts insuilin resistance in high risk individuals. Diabetes Care. 2009;32(6):1081-6.

32. Brown $W$, Miller $Y$, Miller R. Sitting time and work patterns as indicators of overweight and obesity in Australian adults. Int J Obes. 2003;27(11):1340.

33. Thorp AA, Healy GN, Winkler E, Clark BK, Gardiner PA, Owen N, Dunstan DW. Prolonged sedentary time and physical activity in workplace and non-work contexts: a cross-sectional study of office, customer service and call Centre employees. Int J Behav Nutr Phys Act. 2012;9(1):128.

34. McCrady SK, Levine JA. Sedentariness at work: how much do we really sit? Obesity. 2009;17(11):2103-5.

35. Chau JY, van der Ploeg HP, Van Uffelen JG, Wong J, Riphagen I, Healy GN, Gilson ND, Dunstan DW, Bauman AE, Owen N. Are workplace interventions to reduce sitting effective? A systematic review. Preventive Medicine. 2010; 51(5):352-6

36. Dunstan DW, Kingwell BA, Larsen R, Healy GN, Cerin E, Hamilton MT, Shaw JE, Bertovic DA, Zimmet PZ, Salmon J. Breaking up prolonged sitting reduces postprandial glucose and insulin responses. Diabetes Care. 2012;35(5):976-83.

\section{Ready to submit your research? Choose BMC and benefit from:}

- fast, convenient online submission

- thorough peer review by experienced researchers in your field

- rapid publication on acceptance

- support for research data, including large and complex data types

- gold Open Access which fosters wider collaboration and increased citations

- maximum visibility for your research: over 100M website views per year

At BMC, research is always in progress.

Learn more biomedcentral.com/submissions 